\title{
EDITORIAL
}

\section{A personal perspective on personalized medicine}

\author{
NOAM SHOMRON \\ Sackler Faculty of Medicine, Tel Aviv University, Israel, 69978
}

At the upcoming $6^{\text {th }}$ Personalized Medicine World Conference (PMWC) on 30 June 2013, Patrick and Sharon Terry will be sharing their perspective on personalized medicine with Israeli and US clinicians, researchers, executives, entrepreneurs and investors at the Daniel Hotel in Hertzelia, Israel - http:// 2013il.pmwcintl.com.

Sharon and Pat Terry are, on one hand, unlikely participants in the world of personalized medicine. On the other hand, they are exactly the right players. They entered the world of personalized medicine because their two children were diagnosed with a genetic disease in 1994. A college chaplain and a fire protection engineer, they were thrust into a world that seemed chaotic and without structure. There was no real understanding of pseudoxanthoma elasticum (PXE), and though the medical literature made no sense, they could tell there was no associated plan or pattern of the disease. Within days of the diagnosis, researchers' interest from all over was sparked and they took blood samples from the Terrys and their children. When the Terrys recommended to the researchers from different institutions to share their knowledge and results with one another, they were met with incredulous laughter. This focused their early response to the disease and spurred them on to establish a non-profit research foundation for the disease - the first lay-owned and managed blood and tissue bank. They created a clinical registry and began to search for the gene. They discovered the gene in 1999 and subsequently became patent holders, and in their own words 'the steward', for the $A B C C 6$ gene. Pat and Sharon went on to create a genetic test and outlicensed the gene to a small diagnostic company for a lifetime fee of $\$ 100$. They set up a consortium of 36 laboratories that required datasharing between them. This instigated approximately 100 studies in the disease, most recently enabling a clinical trial with the large registry and epidemiological study.

Through all of this it was obvious to them that they were trying to do a small thing in a very broken system. Both have gone on to work in the personalized medicine field. Pat was a co-founder of Genomic Health, working on almost every aspect of the company on its road to going public with a product that has helped hundreds of thousands of women discover whether they have a risk of their cancer reoccurring. He subsequently co-founded the Personalized Medicine Coalition and the European Personalized Medicine agency. Pat is on the board of directors of MeMed Diagnostics in Tirat Carmel Israel. He has advised hundreds of companies in their quest to accelerate applications for personalized medicine. He has dedicated his career to helping people and advancing a patient-centred perspective in research, product development, and translational medicine. He is active internationally with strategic management and financing of precision medicine companies for numerous clinical indications and technologies.

Sharon leads a network of 10000 organizations and is creating novel solutions in participant engagement in biomedical research. Recently, she established Registries for ALL - https://www.reg4all.org - an online tool to help individuals set their sharing and data access preferences so they can participate in a trust environment in biomedical research that will enable personalized medicine. She believes that as many people as possible need to offer their clinical and genetic information on their own terms and create the large associative databases that are needed for personalized medicine to become widespread. If individuals are offered the tools to determine with whom they share their data and how, then they will become more engaged in their own health. Sharon believes that personalized medicine will only come as a result of everyone participating in their own health, determining their sharing preferences, and sharing data as easily as possible.

PMWC International provides a platform to foster collaboration among stakeholders and catalyse change in personalized medicine. Launched by Silicon Valley investors and entrepreneurs in 2009, PMWC has held several conferences in the USA and abroad to forge connections and drive innovation. For more details about the upcoming PMWC 2013 taking place in Israel, please visit their website at http:// 2013il.pmwcintl.com 